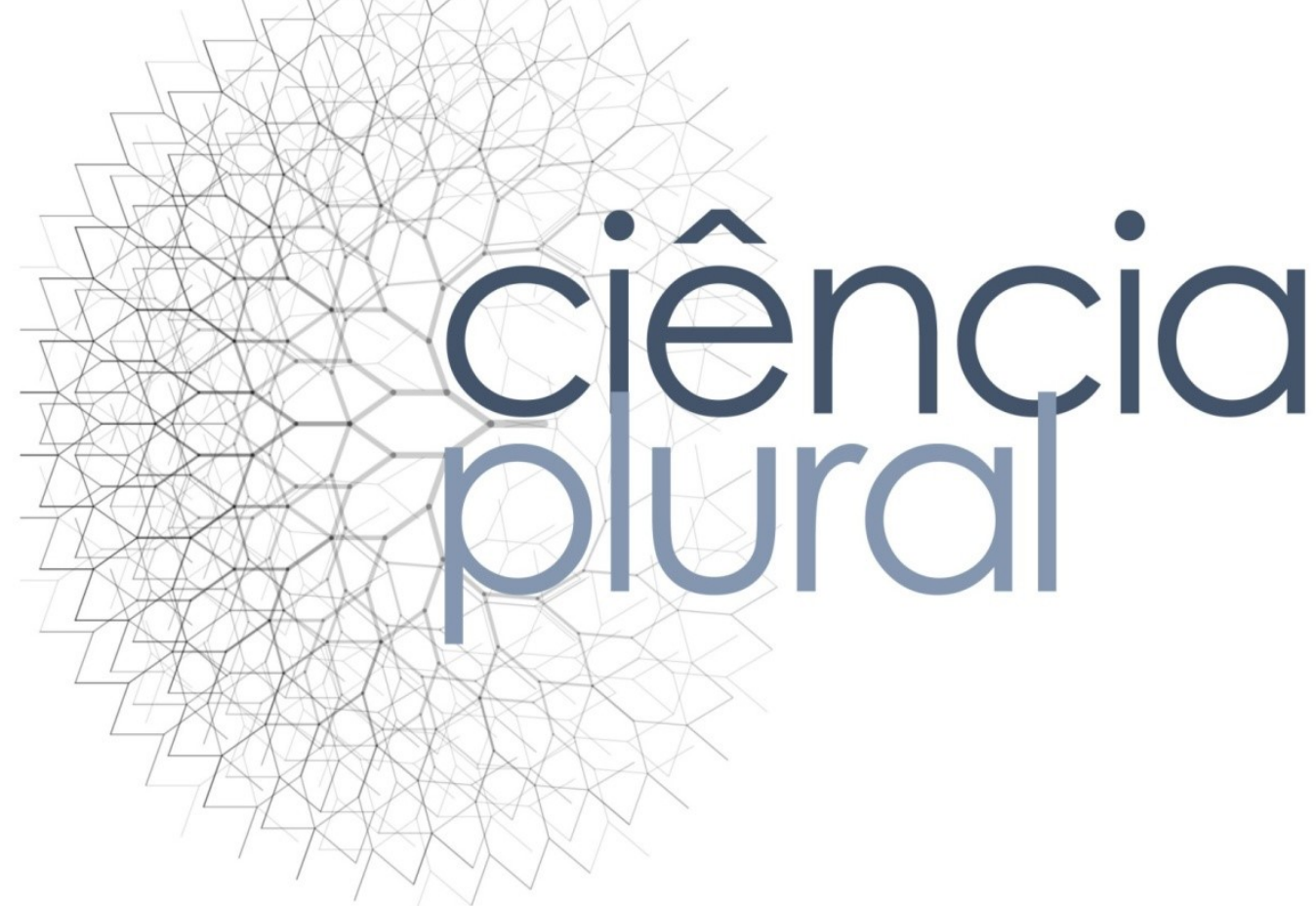

\title{
ESTUDO DA CONCENTRAÇÃO DE FLÚOR NAS ÁGUAS DE ABASTECIMENTO PÚBLICO RELACIONADA ÀS VARIAÇÕES PLUVIAIS
}

\section{Fluoride concentration study in public water supply related to pluvial variations}

Luis Felipe Pupim dos Santos • Mestrando do Programa de Pós-Graduação em Odontologia Preventiva e Social da Faculdade de Odontologia de Araçatuba (FOA-UNESP). Graduação pela FOA-UNESP. E-mail: Ifpupim@hotmail.com

Fernando Yamamoto Chiba - Professor substituto do Programa de Pós-Graduação em Odontologia Preventiva e Social da Faculdade de Odontologia de Araçatuba (FOA-UNESP). Pós-doutorado pela FOAUNESP. E-mail: fernandoychiba@hotmail.com

Suzely Adas Saliba Moimaz • Professora Titular. Pesquisadora do Programa de Pós-Graduação em Odontologia Preventiva e Social da Faculdade de Odontologia de Araçatuba (FOA-UNESP). E-mail: sasaliba@foa.unesp.br

Orlando Saliba • Professor Titular. Programa de Pós-Graduação em Odontologia Preventiva e Social da Faculdade de Odontologia de Araçatuba (FOA-UNESP). Email: osaliba@foa.unesp.br

Autor responsável pela correspondência:

Luis Felipe Pupim dos Santos - Ifpupim@hotmail.com 


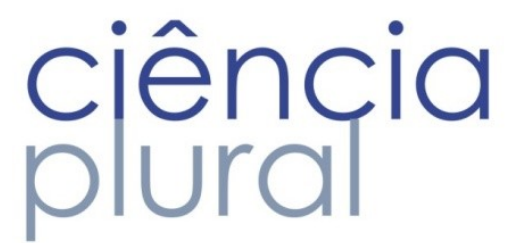

RESUMO

Introdução: Quanto ao uso do flúor na odontologia, a fluoretação das águas de abastecimento público se constitui o método de maior abrangência, além de possuir um baixo custo e ser seguro, porém a análise periódica dos níveis do íon se faz necessária para que se obtenha o máximo benefício na prevenção de cárie e risco mínimo no desenvolvimento de fluorose dentária. Objetivo: analisar e comparar a concentração de flúor nas águas de abastecimento público nos períodos de chuva e seca, em fontes de captação onde o íon é natural, no intervalo de 5 anos (2010-2014). Métodos: a coleta de água ( $\mathrm{n}=2130$ amostras) foi feita em pontos previamente estabelecidos de acordo com o número e localização das fontes de captação de água do município de Birigui-SP. As análises foram executadas com um analisador de íons acoplado a um eletrodo específico para flúor. A análise dos dados foi feita por estatística descritiva e utilizando-se o teste de Wilcoxon para a comparação entre os períodos de chuva e seca. Resultados: $81,03 \%$ das amostras dos poços profundos estavam acima dos teores de flúor recomendados, não estando então na classificação que ofereça o máximo benefício e risco mínimo. Os valores referentes à média, desvio padrão e valores máximos e mínimos foram semelhantes nos dois poços profundos onde o flúor contido é natural. Conclusões: Não houve diferenças estatisticamente significativas nos teores do ín flúor das águas provenientes de poços profundos na comparação dos períodos de chuva e seca.

Palavras-chave: Saúde bucal; Flúor; Fluoretação.

\section{ABSTRACT}

Introduction: Regarding the use of fluoride in dentistry, the water fluoridation is the method more comprehensive, have a low cost and safe, but the periodic analysis of the ion levels is necessary in order to obtain the maximum benefit in the prevention of caries and minimum risk in the development of fluorosis. Objective: To analyze and compare the concentration of fluoride in public water supplies in periods of rain and drought in funding sources where the ion is natural, in the range of 5 years $(2010-2014)$. Methods: the water collection $(n=2130)$ was made in pre-established points according to the number and location of water sources of Birigui city. The analyzes were performed with an ion analyzer coupled to a specific electrode for fluoride. Data analysis was done by descriptive statistics and using the Wilcoxon test for the comparison between the periods of rain and drought. Results: $81.03 \%$ of samples from deep wells were above the recommended fluoride levels, then not being in the classification that provides maximum benefit and minimum risk. The values for the mean, standard deviation and maximum and minimum values were similar in both deep wells where the fluoride contained is natural. Conclusions: There were no statistically significant differences in the fluoride content of water from deep wells in the comparison of periods of rain and drought.

Keywords: Fluoridation; Fluorides; Oral Health. 


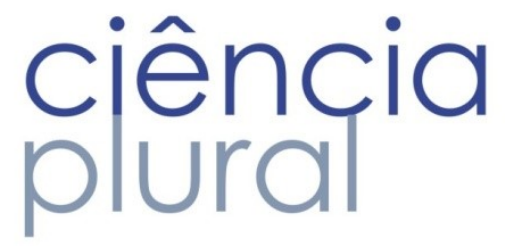

\section{Introdução}

Com a introdução do flúor como fator de prevenção à cárie dentária, observa-se, em grande parte da população mundial, uma diminuição na prevalência desta doença' ${ }^{1}$. Dentre as várias formas de promover 0 consumo ou acesso ao uso do flúor, a fluoretação das águas de abastecimento público constitui-se o método de maior abrangência, baixo custo e seguro². Autoridades e especialistas em saúde consideram o método como uma estratégia fundamental para a prevenção de cárie dentária ${ }^{3}$. É ainda considerada a medida coletiva mais importante da aplicação de flúor em Saúde Pública, desde que respeitadas todas as recomendações e monitoramento periódico da concentração do fluoreto ${ }^{4-7}$. Segundo revisão sistemática de McDonalgh et al. sobre 0 tema, foi evidenciado que em áreas fluoretadas havia um número maior de crianças sem cáries em comparação com regiões não fluoretadas, em vários estudos analisados ${ }^{8}$. A fluoretação das águas de abastecimento público mostrou-se tão eficaz, que o Centro de Prevenção e Controle de Doenças dos Estados Unidos (CDC) considerou o método como uma das 10 principais conquistas da saúde pública no século XX ${ }^{9,10}$.

O teor considerado ótimo de flúor nas águas de abastecimento pode variar conforme a média das temperaturas máximas de cada região, pois isso pode alterar a constância do consumo diário de água da população ${ }^{11,12}$.

Dependendo da fonte de onde a água é proveniente, a concentração do íon flúor pode não estar dentro dos padrões recomendados para consumo, como por exemplo, em localidades que apresentam poços profundos compondo sua rede de distribuição, o nível do fluoreto tende a ser mais elevado ${ }^{13}$. Do mesmo modo, poços semiartesianos, fontes alternativas e a água proveniente da Estação de Tratamento possuem características específicas que podem causar diferenças quando se compara o teor de flúor considerando suas respectivas procedências $^{13}$.

Estudos sobre o assunto apontam a necessidade de se fazer o controle da manutenção dos teores de fluoreto nas águas de abastecimento público ${ }^{14}$. No Brasil, a legislação estabelece que os órgãos responsáveis pelo tratamento da água devem monitorar sua qualidade, entretanto o heterocontrole, que consiste na análise periódica da fluoretação das águas por parte de instituição distinta daquela responsável pelo tratamento e abastecimento de água, é uma importante estratégia de auxílio para que o método atinja seu máximo benefício na prevenção de cárie dentária e o risco mínimo no desenvolvimento de fluorose ${ }^{7}$.

Sendo assim, se faz necessário um conhecimento mais amplo acerca dos fatores naturais ou humanos que possam interferir na fluoretação adequada das águas de abastecimento público e consequentemente na eficácia 


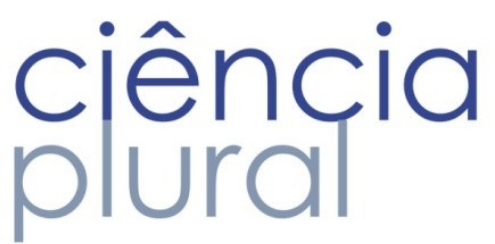

do método na prevenção de cárie. Nesse contexto, o objetivo neste estudo foi analisar e comparar a concentração de flúor nas águas de abastecimento público nos períodos de chuva e seca, em fontes de captação onde o íon é natural, em um intervalo de 5 anos (2010-2014).

\section{Metodologia}

A pesquisa foi realizada em Birigui, um município do noroeste do estado de São Paulo, com complexa rede de distribuição de água que inclui poços profundos, poços semiartesianos, Estação de Tratamento (ETA), mistura das águas de poços profundos com ETA, e fontes alternativas, consideradas poços de indústrias ou empresas onde a população coleta água, geralmente em torneiras da parte exterior do estabelecimento. Porém, para esse estudo, apenas as amostras procedentes dos poços profundos foram comparadas nos períodos de chuva e seca, pois o flúor contido neles é de origem natural. Há no município dois poços profundos: o Áqua Pérola (poço profundo 1) e o Matéria (poço profundo 2).

Os pontos de coleta das amostras foram identificados de acordo com a quantidade e localização das fontes de abastecimento de água existentes na localidade. Determinou-se, para cada fonte de água de abastecimento no município, 3 pontos de coleta na área abastecida por ela, com exceção das fontes alternativas, em que para cada fonte existe apenas 1 , totalizando 42 pontos. Foram selecionados os endereços dos pontos de coleta de água por conveniência, sendo todos em locais públicos (postos de saúde, escolas e outros) em razão da facilidade de acesso. Foram estabelecidos contatos formais, durante o desenvolvimento do estudo, com o Secretário de Saúde, o Coordenador de Saúde Bucal e com o responsável pelo abastecimento de água do município.

As coletas das amostras de água foram realizadas sempre na primeira semana de cada mês, realizadas diretamente da rede de abastecimento. Frascos de polietileno de $40 \mathrm{ml}$, previamente descontaminados com água deionizada com objetivo de evitar a contaminação, foram usados para armazenar a água coletada. Os mesmos foram hermeticamente fechados, recebendo uma etiqueta de identificação, com dados referentes ao procedimento de coleta da amostra, indicando o local, dia, mês, hora em que a mesma foi realizada e o nome da pessoa responsável pela coleta. Concluída a coleta, as amostras foram transportadas até o laboratório do Núcleo de Pesquisa em Saúde Coletiva (NEPESCO) do Programa de Pós-graduação em Odontologia Preventiva e Social da Faculdade de Odontologia de Araçatuba - UNESP, onde as análises, no período máximo de 150 dias, foram realizadas. 


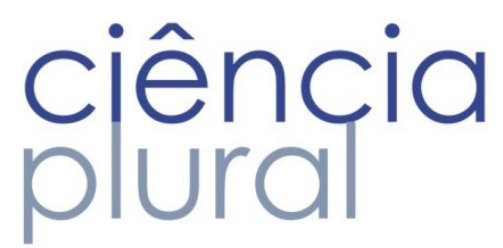

Foram coletadas e analisadas, em duplicata, 2130 amostras relativas aos meses de estudo levando-se em consideração todas as fontes de captação do município e todos os meses do ano, de Janeiro a Dezembro, durante os 5 anos do período de estudo. Referentes aos dois poços profundos, 313 amostras foram analisadas.

Para a execução nas análises laboratoriais, utilizou-se um analisador de íns (Model 940EA; Orion Research, Inc., Beverly, MA, USA) acoplado a um eletrodo combinado para flúor (Model 9609BN; Orion Research, Inc.), segundo o método descrito por Maia et al. ${ }^{15}$ para a mensuração deste íon.

Para se reduzir a margem de erro, a calibração do equipamento foi realizada em triplicata, por meio da construção de uma curva de calibração, levando-se em consideração os valores esperados para as amostras com padrões variando de 0,1 a 2,0 mgF/L. Foram utilizadas diluições a partir de uma solução padrão de fluoretos a 100 $\mathrm{mg} / \mathrm{L}$ (Orion, 940907). De cada um dos 5 padrões, foi coletado um volume de $1 \mathrm{ml}$, posteriormente acrescido de 1 ml de "Total lonic Strenght Adjustor Buffer" (TISAB II), um tampão de ajuste de pH, força iônica e descomplexante, muito utilizado nas análises de flúor. Após executada a curva de calibração e estando o equipamento apto para a realização das análises, é realizada a leitura das amostras, em duplicata, também sendo adicionado o composto TISAB II, na proporção de 1:1. Os valores obtidos no analisador de íons são em milivolts $(\mathrm{mV})$, e ao serem repassados para uma planilha eletrônica no Microsoft Office Excel, convertem-se em miligramas de flúor por litro $(\mathrm{mgF} / \mathrm{L})$.

Os resultados das análises das amostras foram enviados mensalmente aos responsáveis pelo tratamento de água, secretário de saúde e coordenador de saúde bucal do município. Para a classificação das amostras quanto ao teor de flúor foi empregada a recomendação elaborada pelo Centro Colaborador do Ministério da Saúde em Vigilância da Saúde Bucal (CECOL), a qual se baseia no princípio de maior benefício para prevenção da cárie e menor risco de desenvolver fluorose dentária, analisando a média das temperaturas máximas anuais de cada localidade. Para o município do estudo, o intervalo recomendado varia de 0,55 a 0,84 mgF/L 12 .

Os meses considerados com presença de chuva foram janeiro, fevereiro, março e abril, enquanto os meses de seca foram maio, junho, julho e agosto, e assim foi feita a divisão dos períodos de alta e baixa pluviosidade, respectivamente ${ }^{16}$. Para análise dos dados utilizou-se estatística descritiva e 0 teste de Wilcoxon para a comparação entre os períodos de chuva e seca. 


\section{ciência \\ plural}

Resultados

Nota-se na tabela 1 que os poços profundos apresentaram as maiores médias, tanto no período de chuva quanto na seca. Constatou-se também que $81,03 \%$ das amostras dos poços profundos estavam acima dos teores de flúor recomendados, portanto fora do intervalo que oferece o máximo benefício na prevenção de cárie e risco mínimo de fluorose.

Tabela 01: Médias (e desvio padrão) da concentração de flúor ( $\mathrm{mgF} / \mathrm{L}$ ) de cada fonte de

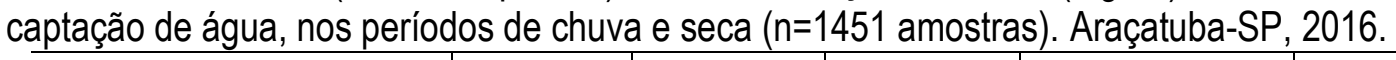

\begin{tabular}{l|c|c|c|c|c}
\hline & ETA* & $\begin{array}{c}\text { Poços } \\
\text { profundos }\end{array}$ & $\begin{array}{c}\text { PTA + } \\
\text { Proços } \\
\text { Profundos }\end{array}$ & $\begin{array}{c}\text { Poços } \\
\text { semiartesianos }\end{array}$ & $\begin{array}{c}\text { Fontes } \\
\text { alternativas }\end{array}$ \\
\hline Chuva (jan, fev, mar, abr) & $0,78(0,14)$ & $1,11(0,08)$ & $0,92(0,15)$ & $0,80(0,29)$ & $0,09(0,02)$ \\
\hline Seca (maio, jun, jul, ago) & $0,83(0,26)$ & $1,11(0,13)$ & $0,97(0,27)$ & $0,85(0,29)$ & $0,11(0,05)$ \\
\hline
\end{tabular}

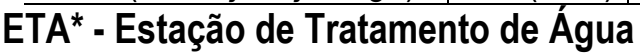

Tabela 02: Distribuição percentual das amostras de água segundo o teor de flúor referentes aos 5 anos de análise, sem distinção dos períodos de chuva e seca (n=2130 amostras). Araçatuba-SP, 2016.

\begin{tabular}{l|c|c|c|c|c}
\hline mgF/L & ETA & $\begin{array}{c}\text { Poços } \\
\text { Profundos }\end{array}$ & $\begin{array}{c}\text { ETA + poços } \\
\text { profundos }\end{array}$ & $\begin{array}{c}\text { Poços } \\
\text { Semiartesianos }\end{array}$ & $\begin{array}{c}\text { Fontes } \\
\text { Alternativas }\end{array}$ \\
\hline$<\mathbf{0 , 5 5}$ & 4,57 & 0,64 & 1,3 & 12,6 & 100 \\
\hline de $\mathbf{0 , 5 5}$ a $\mathbf{0 , 8 4}$ & 56,13 & 18,33 & 17,8 & 37,56 & 0 \\
\hline de $\mathbf{0 , 8 5}$ a $\mathbf{1 , 1 4}$ & 34,19 & 52,41 & 57,6 & 37,48 & 0 \\
\hline$>\mathbf{1 , 1 4}$ & 5,11 & 28,62 & 23,3 & 12,36 & 0 \\
\hline Total & 100 & 100 & 100 & 100 & 100 \\
\hline
\end{tabular}


Tabela 03: Média, desvio padrão, valores mínimo e máximo referentes aos teores de flúor nos períodos de chuva e seca dos poços profundos 1 e 2, e valores de "t" e " $p$ " do teste estatístico realizado para comparação entre os períodos $(n=210$ amostras). Araçatuba-SP, 2016.

\section{ciência plural}

\begin{tabular}{|c|c|c|c|c|}
\hline & \multicolumn{2}{|c|}{ POÇO PROFUNDO 1} & \multicolumn{2}{|c|}{ POÇO PROFUNDO 2} \\
\hline & CHUVA & SECA & CHUVA & SECA \\
\hline Média & 1,1 & 1,13 & 1,1 & 1,12 \\
\hline Desvio padrão & 0,11 & 0,11 & 0,07 & 0,10 \\
\hline Mínimo & 0,72 & 0,74 & 0,81 & 0,7 \\
\hline Máximo & 1,29 & 1,36 & 1,23 & 1,35 \\
\hline Valor de"t" & \multicolumn{2}{|c|}{331} & \multicolumn{2}{|c|}{328} \\
\hline Valor de "P" & \multicolumn{2}{|c|}{0,086} & \multicolumn{2}{|c|}{0,080} \\
\hline
\end{tabular}

Os valores referentes à média, desvio padrão e valores mínimos e máximos de flúor foram semelhantes nessas duas fontes. Pelo teste de Wilcoxon, não houve diferenças estatisticamente significativas entre os períodos de chuva e seca nos dois poços profundos analisados (Tabela 3).

\section{Discussão}

A fluoretação das águas de abastecimento público mostra-se a maneira mais eficaz de expandir os benefícios da ação do íon na prevenção da cárie dentária, porém, para que haja a otimização do método, é necessária uma vigilância periódica dos níveis de flúor presentes na água, visto que concentrações abaixo do ideal não geram o efeito desejado e concentrações acima do recomendado podem acarretar em fluorose dentária ${ }^{1,7,10}$.

Sabe-se que, alguns fatores naturais como temperatura, $\mathrm{pH}$, presença ou não de complexos minerais, íons precipitados e colóides, solubilidade de minerais, capacidade de troca iônica de minerais, granulometria e o tipo da litologia e o tempo de resistência das águas, podem influir nos níveis de flúor contido nas águas de determinada região ${ }^{17}$. Quando ocorre a precipitação, seja por chuva ou neve, e a água alcança a superfície do terreno, parte dela se infiltra no solo e a outra escoa na forma de excedente pluvial ${ }^{18}$. Assim sendo, dependendo do grau de permeabilidade do solo, esta água reabastecerá o aquífero do local e ficará em maior contato com as rochas de fluorita, podendo diluir o nível de flúor contido nela.

Na literatura, quando se busca os termos 'fluoretação' e 'temperatura', a maioria dos resultados obtidos é de estudos que dizem respeito à quantidade considerada ótima de flúor nas águas de abastecimento público de 


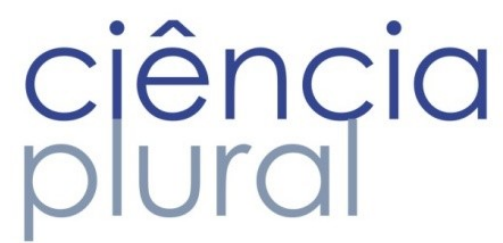

acordo com a temperatura de cada região, e poucas pesquisas relacionadas a possíveis variações dos níveis de flúor de acordo com as mudanças de estação são encontradas. Nas buscas dos termos 'fluoretação' e 'pluviosidade' nas bases de dados, poucos estudos são localizados. Essa escassez de artigos sobre 0 assunto baseou a proposição deste estudo, representada pela dúvida: na época de chuvas, a maior precipitação poderia diluir o flúor contido naturalmente nas águas, alterando assim seus parâmetros normais?

Pôde-se notar, pelos resultados obtidos neste estudo que, nas fontes de captação onde o flúor é de origem natural, ou seja, nos dois poços profundos, não houve diferenças estatisticamente significativas nos períodos usados para comparação (chuva e seca). Com relação às médias, desvios padrões e valores máximos e mínimos, os poços profundos 1 e 2 apresentaram resultados semelhantes tanto na chuva quanto na seca, o que evidenciou que essas fontes se comportaram de maneira regular independente da estação, ou seja, a suposição de que as águas das chuvas pudessem diluir o flúor dessas fontes não foi comprovada. Os valores obtidos pelas análises desses dois poços mostraram que eles obtiveram maiores médias referentes aos níveis do fluoreto em relação às outras fontes de captação. Esse fenômeno já foi evidenciado por outro estudo13, mostrando que há uma tendência de que os teores de flúor em poços profundos sejam mais elevados quando comparados às outras fontes de captação. No município de estudo, na tentativa de diluir as águas provenientes dos poços profundos Áqua Pérola e Matéria a fim de se conseguir teores menos elevados do íon, foi feita a mistura das águas dessas fontes com as águas da Estação de Tratamento.

Em uma pesquisa que comparou as fontes de captação, sendo elas Estação de Tratamento ( $n=158)$, poços profundos $(n=311)$, junções de tubulação de poços profundos com Estação de Tratamento (313), poços semiartesianos $(n=1285)$ e fontes alternativas $(n=63)$, só não houve diferenças estatisticamente significantes quando foi comparada a água proveniente da estação de tratamento e dos poços semiartesianos, utilizando-se uma análise de variância $(p<0,05)^{16}$.

Mais um estudo realizado sobre a influência das variações pluviais no teor de flúor das águas de abastecimento oriundas de poços profundos mostrou que não houve diferenças estatísticas na comparação dos meses de seca e de chuva em relação à concentração do fluoreto, corroborando com 0 achado na presente pesquisa ${ }^{16}$. Outro estudo, conduzido em Piracicaba, São Paulo, em que o objetivo foi averiguar se a temperatura interferiu nos teores de flúor das águas, evidenciou que as concentrações mantiveram-se semelhantes mesmo com as diferenças climáticas no verão e inverno ${ }^{19}$. Ramires (2006), em uma pesquisa sobre a fluoretação das águas de abastecimento público de Bauru, São Paulo, também constatou que não houve variações nos níveis de flúor natural contido na água em razão da sazonalidade das estações do ano20. 


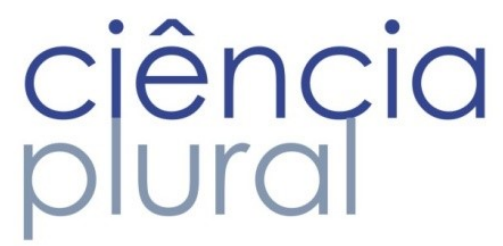

Segundo um estudo de revisão sistemática realizado por McDonalgh et al. ${ }^{8}$, a evidência da redução de cárie deve ser considerada em conjunto com o aumento da prevalência de fluorose dental, reforçando o fato de que a fluoretação necessita de vigilância constante para que os riscos sejam diminuídos ou extinguidos.

A fluoretação das águas de abastecimento público é uma medida de saúde pública consagrada e recomendada por várias organizações de ciência e saúde, dentre elas, Associação Internacional de Pesquisa Odontológica (IADR), Federação Dentária Internacional (FDI), Organização Pan-Americana de Saúde (OPAS), e Organização Mundial da Saúde $(\mathrm{OMS})^{14}$. Porém, muito se discute sobre os possíveis riscos ${ }^{21}$, sobre a necessidade de se realizar a vigilância e heterocontrole $2-7$, e sobre as recomendações para os teores considerados ótimos do íon flúor22, fazendo com que o tema ainda esteja em rodas de discussão e presente em muitos estudos, mesmo após sua eficácia e importância na redução de cárie da população nos últimos anos já terem sido comprovadas $^{23}$, sendo que alguns estudos ainda encontraram relação entre melhores IDH-M (índice de desenvolvimento humano municipal) e tempo de fluoretação das águas de abastecimento público ${ }^{24}$.

Países que não têm a fluoretação da água, em sua maioria, não são contra o método, em geral não 0 introduziram por uma série de razões, dentre elas, o uso de outras práticas preventivas à população, como a fluoretação do sal e programas nacionais de cuidados com a saúde bucal ${ }^{9}$.

\section{Conclusões}

Não houve diferenças estatisticamente significativas nos teores do íon flúor das águas provenientes de poços profundos na comparação dos períodos de chuva e seca no município estudado. Os poços profundos apresentaram médias de fluoreto maiores que outras fontes de captação.

O Brasil, com sua vasta extensão territorial, possui condições climáticas distintas em suas regiões e, sendo assim, estudos semelhantes poderiam ser realizados em localidades que apresentem características pluviais diferentes do município de Birigui alvo deste estudo. 0 conhecimento mais aprofundado das variáveis que possam influir nos benefícios da fluoretação se faz necessário a fim de que o método continue auxiliando na redução da prevalência de cárie em todas as camadas da população sem oferecer nenhum tipo de risco. 


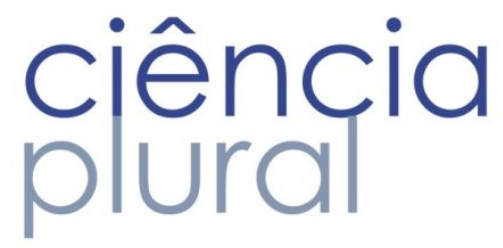

\section{Referências}

1. Brasil. Fundação Nacional de Saúde. Manual de Fluoretação da Água para Consumo Humano. Brasília: Funasa, 2012. $72 \mathrm{p}$.

2. Narvai PC. Cárie dentária e flúor: uma relação do séc. XX. Ciênc Saúde Coletiva 2000; 5(2):381-392.

3. Iheozor-Ejiofor Z, Worthington HV, Walsh T, O'Malley L, Clarkson JE, Macey R, et al. Water fluoridation for the prevention of dental caries. Cochrane Database of Systematic Reviews 2015; 6: CD010856.

4. Newbrun E. Effectiveness of water fluoridation. J Public Health Dent 1989; 49(Spec 5):279-289.

5. Ripa LW. A half-century of community water fluoridation in the United States: review and commentary. J Public Health Dent 1993; 53(1):17-44.

6. Horowitz HS. The effectiveness of community water fluoridation in the United States. J Public Health Dent 1996; 56(Spec 5): 253-258.

7. Locker D. Benefits and risks of water fluoridation. An Update of the 1996 Federal-Provincial Sub-committee Report. Toronto: Ontario Ministry of Health, 1999. [capturado em 2010 abr. 06]. Disponível em: http://www.health.gov.on.ca/english/public/pub/ministry_reports/fluoridation/fluor.pdf.

8. McDonalgh MS, Whiting PF, Wilson PM, Sutton AJ, Chestnutt I, Cooper J, et al. Systematic review of water fluoridation. BMJ 2000; 321(7265): 855-859.

9. Armfield JM. When public action undermines public health: a critical examination of antifluoridationist literature. Aust New Zealand Health Policy 2007; 4(25):01-13.

10. Centers for Disease Control and Prevention (CDC). Achievements in Public Health, 1900-1999. Fluoridation of drinking water to prevent dental caries. Morbidity and Mortality Weekly Report 1999; 48(41): 933940.

11. Galagan DJ, Vermillion JR. Determining optimum fluoride concentrations. Public Health Rep 1957; 72(6): 491-493.

12. Centro Colaborador do Ministério da Saúde em Vigilância da Saúde Bucal (CECOL/USP). Consenso técnico sobre classificação de águas de abastecimento público segundo o teor de flúor. São Paulo: Faculdade de Saúde Pública da Universidade de São Paulo; 2011.

13. Moimaz SAS, Santos LFP. Estudo longitudinal da fluoretação das águas em municípios com complexa rede de distribuição: dez anos de estudo. Arch Health Invest 2015; 4(5):11-16.

14. Zimmer S, Jahn KR, Barthel CR. Recommendations for the use of fluoride in caries prevention. Oral Health Prev Dent 2003; 1(1):45-51.

15. Maia LC, Valença AMG, Soares EL, Cury JA. Controle operacional da fluoretação da água de Niterói, Rio de Janeiro, Brasil. Cad Saúde Pública 2003; 19(1):61-67. 
16. Moimaz SAS, Araújo PC, Chiba FY, Garbin CAS, Sumida DH, Saliba NA. Influência das variações pluviais nos teores de flúor em águas de poços. UFES. Rev Bras Pesqui Saúde 2012; 14(1):36-41.

17. Apambire WB, Boyle DR, Michel FA. Geochemistry, genesis and health implications of floriferous ground waters in the upper regions of Ghana. Environ Geol 1997; 33(1):13-24.

18. Guimarães SM. Investigação da ocorrência de fluorose associada ao consumo de água subterrânea na região nordeste do estado de Goiás utilizando sistema de informações geográficas [Trabalho de Conclusão de Curso]. Goiânia: Centro Federal de Educação Tecnológica do Estado de Goiás; 2006.

19. Amaral RG, Wada RS, Sousa MLR. Fluoride concentration in public water supply related to temperature in Piracicaba - SP. RFO 2007; 12(3):24-28.

20. Ramires I, Maia LP, Rigolizzo DS, Lauris JRP, Buzalaf MAR. Heterocontrole da fluoretação da água de abastecimento público em Bauru, SP, Brasil. Rev Saúde Pública 2006; 40(5):883-889

21. Podgorny PC, McLaren L. Public perceptions and scientific evidence for perceived harms/risks of community water fluoridation: An examination of online comments pertaining to fluoridation cessation in Calgary in 2011. Can J Public Health 2015; 106(6): e413-e425.

22. Spencer AJ, Do LG. Caution needed in altering the 'optimum' fluoride concentration in drinking water. Community Dent Oral Epidemiol 2016; 44(2):101-108.

23. Narvai PC, Frazão P, Castellanos RA. Declínio da experiência de cárie em dentes permanentes de escolares brasileiros no final do século XX. Rev Odontol Soc 1999; 1(1/2):25-29.

24. Bueno RE, Moyses ST, Bueno PAR, Moyses SJ. Determinantes sociais e saúde bucal de adultos nas capitais do Brasil. Rev Panam Salud Publica 2014; 36(1):17-23. 